\title{
A coordenação pedagógica e a gestão escolar: desafios na perspectiva da educação inclusiva
}

\section{Teaching coordination and school management: challenges in inclusive education view}

Lá codinación pedagogica y la gestión escolar: retos en la perspectiva da la educación inclusiva

Heitor Romero Marques ${ }^{1}$ Adriana Cristina Lopes Martins ${ }^{2}$

${ }^{1}$ Licenciado em Ciências e Pedagogia, Especialista em Filosofia e Historia da Educação, Mestre em Educação- formação de professores, Doutor em Desarrollo Local y planteamiento territorial. Universidade Católica Dom Bosco, Campo Grande, Mato Grosso do Sul. E-mail: heiroma@ucdb.br.

${ }^{2}$ Licenciada em Pedagogia, Especialista em Educação Inclusiva. Universidade Católica Dom Bosco, Campo Grande, Mato Grosso do Sul. E-mail: adrianaclm2009@hotmail.com. 
Resumo: Este artigo tem por objetivo apresentar um estudo sobre as contribuições que o serviço da coordenação pedagógica pode dispensar à educação inclusiva, no âmbito da educação básica. O artigo, portanto, pretende explicitar, no primeiro momento, os aspectos relacionados às funções atribuídas à coordenação pedagógica; para tanto, faz-se um breve estudo sobre as vertentes defendidas pelos especialistas no assunto. A etapa seguinte discorre sobre a educação inclusiva, sobre seus avanços e sobre seus reais objetivos. $O$ estudo está construído a partir das produções teóricas de pesquisadores brasileiros que se concentraram em pesquisar essa temática. A pesquisa segue o caráter de investigação bibliográfica; sendo assim, está preocupada em discorrer sobre a inclusão e como esta vem sendo trabalhada no âmbito da escola comum, bem como sobre as contribuições que o coordenador pedagógico pode dispensar para concretização desse modelo de educação.

Palavras-chave: gestão escolar; prática pedagógica; educação inclusiva.

\begin{abstract}
This article aims to present a study on the contributions that the service of pedagogical coordination can dispense inclusive education as part of basic education. The article therefore aims to clarify, at first, the aspects related to the functions assigned to coordinating education, therefore, it is a brief study of the aspects advocated by experts. The next step discusses inclusive education on their progress and on their real goals. The study is built from the theoretical production of Brazilian researchers who focused on researching this subject. The research follows the character of bibliographic research, therefore, is concerned to discuss the inclusion and how this has been worked in the common school as well as on the contributions that the pedagogical coordinator can dispense for achieving this model of education.
\end{abstract}

Keywords: school management; pedagogical practice; inclusive education.

Resumen: Ese artículo tiene por objetivo presentar um estúdio sobre las contribuciones que el servicio de la cordinación pedagógica puede dispensar a la educación inclusiva, en el ámbito de la educación básica. El artículo, por lo tanto, pretende explicar en el primer momento los aspectos relacionados a las funciones atribuidas a la coordinación pedagógica, por lo tanto, hace un breve estudio sobre variables defendidas por expertos en el asunto. La etapa siguiente descorre sobre la educación inclusiva, sobre sus avances y sobre sus reales objetivos. El estudio está construido a partir de las producciones teóricas de investigadores brasileños que concentraran en investigar esa temática. La investigación sigue el carácter de investigación bibliográfica, y siendo así, está preocupada en versar sobre la inclusión y como esta viene siendo trabajada en el ámbito de la escuela común, bien como, sobre las contribuciones que el coordinador pedagógico puede dispensar para concretización dese modelo de educación.

Palabras claves: gestión escolar; práctica pedagógica; educación inclusiva. 


\section{INTRODUÇÃO}

A educação brasileira nesses últimos anos tem experimentado grandes mudanças, algumas dessas com grande sucesso, outras, nem tanto. Dentre essas muitas transformações, estão as questões relacionadas à inclusão escolar. A educação inclusiva nesses últimos anos avançou grandemente em todo mundo, e aqui no Brasil não tem sido diferente.

É verdade que a execução com qualidade da inclusão escolar ainda precisa sofrer grandes ajustes, mas, de um modo geral, tem caminhado para isso. Assim, quando pensamos nos aprimoramentos para a educação inclusiva, inevitavelmente, nos remetemos à figura do coordenador pedagógico, e nas contribuições que esse profissional pode dar nesse contexto.

Partindo do pressuposto de que o coordenador pedagógico é a pessoa que na escola acompanha mais de perto o trabalho dos professores, sem sombra de dúvidas, esse profissional tem muito a contribuir nos avanços que precisam ser conquistados pela educação inclusiva.

Particularmente, este artigo objetiva discorrer sobre as contribuições que esse profissional pode dar à inclusão escolar, para que essa de fato ocorra, de modo a potencializar seus resultados. Trata-se de uma pesquisa bibliográfica que contempla o pensamento dos principais teóricos brasileiros concernente às questões acima apresentadas, qual seja, a educação inclusiva e as contribuições da coordenação pedagógica.

Os procedimentos metodológicos que estruturam a base desta investigação buscam atender a necessidade de cientificidade a que se propõe a pesquisa científica ao alicerçar a base teórica e a compreensão empírica. Nesse sentido, a pesquisa baseou-se nos procedimentos sugeridos por Minayo (1993), notadamente quanto ao prisma filosófico, em que a considera como atividade básica das ciências na sua indagação e descoberta da realidade. Isto posto, consideramos que a pesquisa resulta em atitudes práticas e teóricas de permanente busca de resposta aos problemas que afligem a humanidade.

Diante dessa perspectiva, a presente pesquisa se pautou nos moldes sugeridos por Silva e Menezes (2005), objetivando gerar conhecimentos para aplicação prática, dirigidos à solução de problemas específicos, no caso a inclusão escolar. 
Do ponto de vista da abordagem, a pesquisa pode ser classificada como sendo descritivo-analítica, considerando que o objetivo principal foi analisar as contribuições da coordenação pedagógica na promoção da inclusão educacional. A pesquisa, em seu viés bibliográfico, adotou as orientações de Severino (2002), no sentido de explicar um problema a partir de referências teóricas e publicadas em documentos. Dito de outra forma, a pesquisa bibliográfica buscou conhecer e analisar as contribuições culturais ou científicas do passado, existentes sobre o assunto em epígrafe.

\section{A FUNÇÃO DO COORDENADOR PEDAGÓGICO}

Quando pensamos sobre os desafios que a educação inclusiva ainda tem que galgar na educação básica (leia-se da educação infantil ao ensino médio), inevitavelmente, nos remetemos à palavra mudanças, que precisam ocorrer para que de fato a inclusão aconteça. Sendo assim, torna-se relevante discorrer sobre a função do coordenador pedagógico nesse contexto.

Vasconcellos (2008), refletindo sobre a função dos ditos "especialistas em educação", traz à tona uma discussão, um questionamento um tanto intrigante, quando indaga: "[...] a escola pode funcionar sem eles? Sem professor e aluno, com certeza não temos escola, mas sem técnicos é possível sua existência ?".

É verdade que, por muito tempo, o papel do coordenador pedagógico no âmbito escolar esteve associado à figura de um profissional que cobrava periodicamente fichas e cadernos devidamente preenchidos, planos de ensino bem elaborados. Que transmitia recados aos professores na hora do intervalo, sendo que os recados quase sempre eram de superiores, e a tônica dos recados, quase sempre, estava relacionada com o bom andamento da escola.

Talvez por isso, o questionamento descrito acima, seja feito por um teórico que tem se dedicado a estudar a fundo a complexidade da educação brasileira. Diante dessa realidade, Vasconcellos (2008, p. 73) indaga: "[...] será que o que importa para uma instituição de ensino é simplesmente existir, ou fazê-lo com uma determinada qualidade"?

Diante dessa discussão, fica evidente que uma escola que prima por promover seus educandos e que busca oportunizar o crescimento integral 
da sua clientela, qual seja, o alunado, deva priorizar a qualidade dos seus serviços. O coordenador pedagógico nesse contexto torna-se um integrante indispensável.

Garcia (1986) assegura que, antes de tudo, o coordenador pedagógico deve enxergar-se como um educador. O referido autor justifica seu pensamento, explicando que, com a visão de que o coordenador deva ser um educador, ele terá condições de contribuir para a construção de novos saberes no grupo em que atua. Aproveitando-se da função em que ocupa na concepção de Garcia (1986), o coordenador pode inclusive, "entrecruzar" seu pensamento com outras maneiras de pensar, no caso, com o pensamento dos professores. A referida autora conclui que, com tal postura, o coordenador pedagógico deixará de ser apenas um "coletivizador de informações".

Ampliando esse pensamento, Conceição (2010, p. 35) esclarece que o coordenador pedagógico tem "[...] a possibilidade de agir como produtor de situações educacionais e articular os profissionais responsáveis pelos diferentes tipos de saber".

Para Garcia (1986), é função primária do coordenador pedagógico estabelecer ligações entre os vários condutos de conhecimento existentes na realidade de uma escola. Um fato que pode exemplificar tal afirmação, é o que ocorre nas disciplinas das áreas exatas. O professor de física explica os fenômenos e se detém mais nisso, enquanto que o professor de matemática, explica os algoritmos que são utilizados na física. Seria interessante e altamente recomendado que houvesse uma interação entre áreas e disciplinas.

o Coordenador, ao mesmo tempo em que acolhe e engendra, deve ser questionador, desequilibrador, provocador, animando e disponibilizando subsídios que permitam o crescimento do grupo; tem, portanto, um papel importante na formação continuada dos educadores, ajudando a elevar o nível de discernimento. Sendo assim, Garcia (1986) julga ser atribuição do Coordenador possibilitar a troca entre os docentes, de modo que possam existir momentos de confronto de ideias, e que estas colaborem para o crescimento do grupo, o que resultará, sem sombra de dúvidas, numa maior apropriação de conhecimento por parte de todos os envolvidos.

É verdade que nem sempre esses encontros dependem apenas da articulação de um Coordenador compromissado e com visão plenas das 
questões que envolvem a educação; na maioria das situações, para que essa prática de fato aconteça, ele deverá "convencer" seus superiores sobre a relevância de tais encontros, que em última instância resulta em benefícios para escola como um todo.

Sobre o papel a ser desempenhado pelo Coordenador junto à instituição, Conceição (2010, p. 35) destaca que "[...] perante a instituição, é o responsável pelas ações de uma equipe e o interlocutor qualificado dos participantes desse segmento (professores, alunos, pais e funcionários) junto à direção da escola e à sociedade".

Outra situação muito comum no ambiente escolar e que repercute negativamente nesse bojo, é a negação de responsabilidades, essa questão inclusive ocorre com o Coordenador pedagógico. Neste sentido, Conceição (2010, p. 35) pontua:

Temos encontrado com muita facilidade coordenadores pedagógicos que não acompanham o processo de ensino e aprendizagem e, em casos de situações problemáticas, atribuem aos professores toda a responsabilidade pelo fracasso das estratégias. Essa postura demonstra imaturidade da parte dos profissionais para o exercício dessa função e aumenta a insatisfação quanto a esse profissional.

A partir da citação acima, fica evidente ser função do Coordenador pedagógico, participar de maneira significativa na elaboração de estratégias e ensino e, num eventual fracasso, possuir maturidade para assumir as possíveis responsabilidades que lhe cabem. Nesse contexto, quando todos os envolvidos num processo participam efetivamente da sua implementação, pode-se afirmar que o conceito de equipe está alicerçado nesse ambiente.

Para o crescimento do grupo que compõe uma equipe escolar, faz-se necessário desenvolver nesses componentes, certas habilidades e competências para que o trabalho aconteça em equipe.

Perrenoud (2000) escreve em seu livro "Dez novas competências para ensinar", sobre as grandes famílias de competências escolhidas e desenvolvidas por ele; essas competências deveriam nortear as formações iniciais e contínuas, aquelas que contribuem para a luta contra o fracasso escolar e desenvolvem a cidadania, aquelas que recorrem à pesquisa e enfatizam a prática reflexiva. 
O processo no qual está inserida, a escola leva cada vez mais em direção à cooperação profissional; logo, trabalhar em conjunto torna-se uma necessidade, ligando-se mais à evolução do ofício do que a uma escolha pessoal. Nessa direção, o Coordenador pedagógico torna-se o personagem que promove o trabalho em equipe na medida em que facilita o diálogo entre a direção e os professores. É possível afirmar, portanto, que a especificidade da atuação da coordenação pedagógica são os processos de aprendizagem, onde quer que ocorram.

No tópico seguinte, serão abordadas algumas vertentes que estão inseridas no contexto da educação inclusiva e, nesse sentido, a proposta visa oportunizar uma reflexão sobre as atribuições da escola no novo cenário, qual seja, o da inclusão escolar.

\section{A EDUCAÇÃO INCLUSIVA NO ÂMBITO DA EDUCAÇÃO BÁSICA}

A educação inclusiva já está presente na maioria das escolas brasileiras, contando com o amparo legal que essa modalidade de ensino propõe, Oliveira e Poker (2002) afirmam que "[...] na realidade brasileira a proposta da construção de um sistema educacional inclusivo encontra-se amparada legalmente e em princípios teóricos fundamentados em ideais democráticos de igualdade, equidade e diversidade".

$\mathrm{Na}$ verdade, quando se investigam os detalhes de como a proposta de educação inclusiva tem acontecido, nota-se que ainda há muito o que se fazer em termos de avanço real. Para Oliveira e Poker (2002), "[...] as práticas inclusivas se distanciam sobremaneira das proposições teóricas e legais". Mantoan (2005) esclarece que, em muitos casos, o que temos presenciado nas escolas é apenas uma integração das crianças com necessidades especiais no âmbito da educação básica.

Januzzi (2006, p. 84), por sua vez, explica que a integração dos alunos com deficiência está focada em "[...] ajudar as pessoas com deficiência a obter uma experiência tão próxima ao normal possível". A referida autora, comentando sobre a educação nesses moldes pontua:

Sua efetivação podia se dar pela oferta de um continuum de serviços que pudessem garantir ao aluno com deficiência o direito de estar em espaços sociais (dentre eles a escola) que aumentasse sua pro- 
ximidade física com os demais alunos e pessoas (dimensão física), podendo usufruir os mesmos recursos educacionais disponíveis no sistema de ensino, incluindo a classe comum (dimensão funcional), com a intenção de potencializar suas possibilidades de interagir socialmente (dimensão social). (JANUZZI, 2006, p.84.

Como se pode inferir da citação acima, a integração possui aspectos positivos, mas a inclusão se propõe ir além, ou seja, o aluno com deficiência não deve apenas frequentar o mesmo espaço dos alunos que não possuem deficiência, mas a eles devem ser assegurados o direito à apropriação do conhecimento.

Nesse sentido, é preciso aprofundar o entendimento do que de fato constitui a educação inclusiva, e como ela deve ocorrer. Para tanto, é imperioso esclarecer quem são os alunos com necessidades especiais. Para Anache (2010) tendo como base o Parecer n. 17/2001, do Conselho Nacional de Educação, Câmara da Educação Básica), podem ser identificados como sendo:

[...] aqueles que, no decorrer do processo educacional, apresentam dificuldades acentuadas de aprendizagem ou limitações no processo do desenvolvimento que dificultam o acompanhamento das atividades curriculares, em decorrência de causas orgânicas ou vinculadas às condições, disfunções, limitações ou deficiências, dificuldades de comunicação e sinalização diferenciadas dos demais alunos, demandando a utilização de linguagens e códigos aplicáveis. Também se incluem nessa categoria alunos com altas habilidades (superdotação) e facilidade de aprendizagem, expressas no domínio de conceitos, procedimentos e atitudes.

Como se pode depreender, na citação acima existem aspectos relevantes a serem explorados, e o primeiro deles diz respeito ao grau de deficiência que o aluno possui. Na concepção de Anache (2010), todo aluno que possui dificuldades significativas de aprendizagem e que apresenta limitações no processo de apropriação do conhecimento pode ser enquadrado no grupo de educandos com necessidades especiais.

Nesse sentido, a escola deve estar preparada para lidar com " $n$ " situações que podem ser vivenciadas em seu cenário. Infelizmente, nesse contexto, o que se vê atualmente, em número considerável de escolas, é o despreparo para lidar com a educação inclusiva, propriamente dita. 
Outro aspecto relevante da citação de Anache (2010) é o que se refere aos alunos que possuem graus elevados de aprendizagem, os ditos superdotados. Para estes, segundo a referida autora, no âmbito da educação básica deve existir atendimento diferenciado. Faz sentido essa afirmação uma vez que tais alunos, por terem facilidade no aprendizado, precisam receber estímulos constantes, de modo, a desenvolver o respectivo potencial.

É verdade que já existem programas oferecidos pelo MEC, que buscam atender e identificar esses alunos, como por exemplo, as olimpíadas de matemática, física, química, ciências, dentre outras. Mas essas iniciativas e outras de natureza semelhante devem ocorrer no seio da escola e de forma sistemática e costumeira.

Ressaltando o que já foi pontuado anteriormente, Mantoan (2006) destaca algumas práticas que devem ser aplicadas periodicamente no cotidiano das escolas inclusivas. Ela adverte que tais ambientes devem se preocupar em elaborar intervenções e ações que contemplem as diferenças, seja do baixo grau de aprendizado, seja do elevado grau de apropriação de conhecimento.

Mantoann (2006, p. 108) adverte ainda que sem essa prática, o direito desses alunos estará assegurado apenas como "[...] uma obrigação de matricular e manter alunos com necessidades especiais em classes comuns, resultando no recrutamento da rejeição".

Vale ressaltar que essa atitude, do não investimento na qualidade do aprendizado desses educandos, poderá, em longo prazo, resultar em cidadão ainda menos preparados para a vida, do que os que passaram pelas instituições de educação especial, as APAEs. Faz-se tal afirmação, a partir da realidade constatada em adultos que receberam instrução dessas instituições.

Atualmente esses cidadãos, que já são adultos, estão inseridos no mercado de trabalho e alguns até levam uma vida muito próxima do "normal". Infelizmente, muitos também não tiverem essa oportunidade de educação, porque como explica Mantoan (2006), as escolas especiais sempre foram mantidas por entidades filantrópicas, e por isso, nem todos tiveram acesso aos serviços prestados por essas instituições.

O fato é que agora a inclusão está posta como direito, e torna-se necessário que esta aconteça de maneira a primar e valorizar o aprendizado 
de todos os educandos. Nesse contexto, Oliveira e Poker (2002) destaca que o desafio dessa educação está firmado em dois pilares, qual seja, o pilar político-administrativo e o pilar político-pedagógico.

No tocante às questões político-administrativas, Oliveira e Poker (2002, p. 77) explica que "[...] o êxito da educação inclusiva dependerá, em grande medida, da oferta de uma rede de apoio à escola, através do trabalho de orientação, assessoria e acompanhamento do processo de inclusão". Logo, de acordo com Oliveira e Poker (2002), a parte administrativa que regula a escola deve oportunizar condições para que os agentes que estão diretamente envolvidos com a inclusão recebam qualificação e acompanhamento dos outros profissionais especialistas.

Profissionais como psicólogos, fonoaudiólogos, terapeutas ocupacionais, fisioterapeutas, dentre outros, precisam dar sua contribuição à escola, acompanhando, orientando e auxiliando os educadores e os alunos com deficiências. No entanto a implementação para a adequação desses profissionais no ambiente escolar depende, essencialmente, de questões administrativas, o que certamente envolve questões financeiras (JANNUZZI, 2006).

Por outro lado, o pilar que diz respeito às concepções pedagógicas, segundo Oliveira e Poker (2002), está relacionado à dimensão política da escola, com isso, torna-se relevante superar a visão ingênua de neutralidade e objetividade que, por muitos anos, esteve presente no ambiente escolar. Nesse sentido Oliveira e Poker (2002, p. 77) pontuam:

Vários autores (CALDART, 2001; FREIRE, 1983, 1987, 1998; MOYSÉS, 2001; PATTO, 1996; PERRENOUD, 2000, 2001; DUARTE, 2001), vêm denunciando o fracasso da escola em cumprir o processo social de "democratização e construção de uma sociedade mais igualitária e, além disso, [os autores] apontam o perverso papel que a escola vem desempenhando na manutenção das relações opressoras impostas pela sociedade capitalista.

Como frisado na citação acima, durante décadas a escola tem sido advertida por diversos teóricos sobre o seu papel na sociedade, e sobre suas práticas opressoras e segregadoras. Ocorre que, embora as advertências aconteçam, algumas práticas insistem em permanecer e, nesse contexto, os mais prejudicados, sem sombra de dúvidas, são aqueles que precisam mais da atenção da escola, quais sejam, os alunos com deficiência. 
Para Oliveira e Poker (2002), a escola fundamentada nesses dois pilares não tratará todos os alunos da mesma maneira, ou seja, haverá olhares diferenciados a alunos que necessitam dessa concepção. Oliveira e Poker (2002, p. 77) chama a atenção advertindo:

[...] a adoção do princípio da igualdade não é garantia de respeito à diversidade e as diferenças existentes, seja do ponto de vista biológico, cultural, racial, econômico, desconsiderando-se quase que completamente o processo de formação da identidade pessoal.

Na tentativa de achar os responsáveis pela implementação da educação inclusiva, Oliveira e Poker (2002, p. 38) ressaltam:

A construção de um sistema educacional inclusivo exige ações direcionadas e planificadas no âmbito político-pedagógico, decorrentes da política e da administração assumidas pelo município, que viabilizarão ou não, investimentos para a formação continuada do educador e da equipe técnica do departamento de educação municipal [...] Com a municipalização do ensino fundamental, assumindo inclusive o ensino especial, os municípios começaram a enfrentar uma realidade até então desconhecida: lidar com as heterogeneidades de toda ordem no mesmo espaço escolar, incluindo alunos que têm deficiências sensoriais, físicas ou cognitivas.

É evidente que os Estados e a união também possuem responsabilidades nesse desafio, mas os Municípios, de um modo geral, precisam assegurar com qualidade a implantação e a manutenção da educação inclusiva, uma vez que está sob sua responsabilidade oferecer a educação do primeiro ao nono ano.

\section{A EDUCAÇÃO INCLUSIVA NA EDUCAÇÃO BÁSICA E AS CONTRIBUIÇÕES DO COORDENADOR PEDAGÓGICO}

Nesta última etapa desse artigo, serão contempladas algumas questões relacionadas à educação inclusiva e às contribuições que o Coordenador pedagógico poderá dispensar para que esta de fato ocorra, e que aconteça com qualidade.

Segundo Conceição (2010), dentre as funções que cabem ao Coordenador pedagógico, existem algumas que podem ser desenvolvidas 
a partir de uma visão que contemple a educação inclusiva, dentre estas, destacam-se:

Viabilização da proposta pedagógica da instituição; acompanhamento do planejamento dos professores e orientação à equipe de docentes na elaboração do plano de estudo, que engloba estratégias de aulas, objetivos, avaliação do conteúdo e lições de casa, resultando em trabalho personalizado; acompanhamento do desempenho dos alunos; bem como da transparência e da referência no trabalho; viabilização da formação contínua dos docentes; estabelecimento de atmosfera harmônica entre a equipe, trabalhando cooperação, interdisciplinaridade e pesquisa, tornando-os corresponsáveis pelo processo de ensino, dentro dos parâmetros definidos pela instituição; facilitação no relacionamento com pais e comunidade e em seu entendimento. (CONCEIÇÃO, 2010, p. 36).

Na elaboração da proposta pedagógica da escola, o Coordenador pedagógico deve se ater para que se contemplem ações relacionadas ao desenvolvimento da educação inclusiva no ambiente escolar. Esse momento é propício quando todos os segmentos da escola se reúnem, oportunidade em que a coordenação deve propor melhorias na qualidade da educação inclusiva.

Já na orientação que o Coordenador pedagógico dispensa no acompanhamento que presta junto aos professores por ele liderados, tal ocasião torna-se também um momento privilegiado para se abordar situações relacionadas ao aprimoramento da inclusão na sala de aula (VASCONCELLOS, 2008).

Para Conceição (2010), é também função do Coordenador pedagógico viabilizar a formação continuada, que poderia, de vez em quando, contemplar a educação inclusiva, de forma mais específica. Por fim, para essa autora, é função do Coordenador pedagógico contribuir para que o ambiente escolar possua uma atmosfera harmônica, possibilitando que haja cooperação e trabalho em equipe. Nesse sentido, novamente, as concepções sobre a educação inclusiva poderão ser melhoradas e aprimoradas. Para tanto, novamente, a figura do Coordenador pedagógico torna-se primordial.

Complementando essa ideia, Garcia (1996, p. 90), possui uma compreensão do trabalho em grupo que enriquece os pensamentos discorridos 
acima. Ela salienta: "Só nos percebemos como agentes de mudança de uma realidade se esta não se efetuar egoisticamente, através de uma ação vertical, mas cooperativamente, comunitariamente, instrumentalizando para tal mudança no aluno". Assim, de acordo com Garcia (1996, p. 90), as melhorias, os avanços, as conquistas só ocorrerão, quando estiverem associadas a uma integração da equipe que se propõe a fazê-la.

\section{CONSIDERAÇÕES FINAIS}

A educação inclusiva inspira dedicação, compromisso e conhecimento de todos os profissionais que estão envolvidos na sua prática, para que de fato esta ocorra com a qualidade almejada. Conforme visto durante essa reflexão, a educação brasileira começa a avançar nessa vertente, a formalização de leis que asseguram a permanência e o direito desses educandos na escola comum são avanços recentes.

Nesse contexto, o coordenador pedagógico é uma peça fundamental para que a inclusão seja promovida de maneira satisfatória no ambiente escolar das escolas de educação básica, uma vez que esse profissional está diretamente ligado ao "batalhão de frente" da escola, qual seja, os professores. A coordenação pedagógica é o segmento da escola que pode sensibilizar e direcionar o olhar que esses profissionais podem ter com relação à inclusão.

É verdade que, como foi abordado neste estudo, a escola tem um papel político pedagógico a desempenhar concernente à inclusão, e, como salientado, a coordenação pode contribuir muito nesse sentido, no entanto o poder público também tem responsabilidades significativas a contribuir nessa questão. Talvez aí residam os maiores entraves, uma vez que, nem sempre, o poder público tem cumprido com a parte que lhe compete.

Se cada segmento se empenhar para que a inclusão de fato ocorra, ela deixará de ser apenas um sonho e se transformará numa bonita realidade. Afinal, incluir é preciso. Mas que essa inclusão aconteça com qualidade e de fato respeitando as diferenças. 


\section{REFERÊNCIAS}

ANACHE, A. A. Psicologia escolar e educação especial: versões, inserções e mediações. Campo Grande, MS: UFMS, 2010.

CONCEIÇÃO, L. F. Coordenação pedagógica e orientação educacional: princípios e ações em formação de professores e formação do estudante. Porto Alegre: Mediação, 2010.

GARCIA, N. A. R. L. O fazer e o pensar dos supervisores e orientadores educacionais. São Paulo: Edições Loyola, 1986.

JANNUZZI, G. S. de M. A educação do deficiente no Brasil. Campinas, SP: Autores Associados, 2006.

MANTOAN, M. T. E. Inclusão escolar: pontos e contrapontos. São Paulo: Summus, 2006.

MINANAYO, Maria Cecilia de Souza. O desafio do conhecimento. Pesquisa qualitativa em saúde. 5. ed. São Paulo: Hucitec; Rio de Janeiro:ABRASCO, 1993.

2005. Inclusão escolar. O que é? Por quê? Como fazer? São Paulo: Moderna,

OLIVEIRA, A. A. S.; LEITE, L. P. Construção de um sistema educacional inclusivo: um desafio político-pedagógico. Ensaio: Avaliação e Políticas Públicas em Educação, Rio de Janeiro, v. 15, n. 57, p. 511-24, out./dez. 2007. Disponível em: <http://www. scielo.br/scielo.php?script=sci_arttext\&pid=S0104-40362007000400004\&Ing=en \&nrm=iso>. Acesso em: 1으 maio 2011.

OLIVEIRA, A. A. S.; POKER, R. B. Educação inclusiva e municipalização: a experiência em educação especial de Paraguaçu Paulista. Revista Brasileira de Educação Especial, Marília, SP, n. 3, v. 2, p. 233-44, jul./dez. 2002.

PERRENOUD, Fhilippe. Trabalhar em equipe. In: Dez novas competências para ensinar. Tradução de Patrícia Chittoni Ramos. Porto Alegre: Artes Médicas Sul, 2000. p.79-93.

SEVERINO, Antonio Joaquim. Metodologia do trabalho científico. 19. ed. São Paulo: CORTEZ, 2002.

SILVA, Edna Lúcia da; MENEZES, Estera Muszkat. Metodologia da pesquisa e elaboração de dissertação. 4. ed. rev. atual. Florianópolis: UFSC, 2005.

VASCONCELLOS, C. S. Processo de planejamento: In: Planejamento: projeto de ensino - aprendizagem e projeto político pedagógico. São Paulo: Libertad, 2008. 